Tarih Kültür ve Sanat Araştırmaları Dergisi

Vol. 9, No. 1, March 2020

\title{
DOI: 10.7596/taksad.v9i1.2419
}

Citation: Podplota, S. (2020). The Role of Tutorials in Improving the Argumentative Skills of Secondary School Students. Journal of History Culture and Art Research, 9(1), 172-181. doi:http://dx.doi.org/10.7596/taksad.v9i1.2419

\section{The Role of Tutorials in Improving the Argumentative Skills of Secondary School Students}

\section{Svitlana Podplota ${ }^{1}$}

\begin{abstract}
From the standpoint of the person-centered approach aimed at supporting students' active position and independence, the tutor's activity in the educational process of secondary school is revealed. The tutor plays a very important role in the formation of a student's capability. Tutorials focus on improving students' argumentative skills in a particular area of expertise, training self-reflection and teaching to put forward arguments. The article is devoted to peculiarities of applying the tutor's questioning techniques and writing essays in teaching argumentation to secondary school students. The research aims to identify the most effective ways and means of applying the given methods. The complex of modern general scientific methods has been used for task realization: theoretical methods - analysis and synthesis; empirical methods - observational (direct and indirect observation); diagnostic (expert interviews, conversations). As a conclusion, we note that conducting tutorials enables to reflect the theoretical foundations of argumentation and forms the research interest, stimulates the process of decentralization in the argumentation of students and also develops their own moral position.
\end{abstract}

Keywords: Argumentation, Tutorial system of education, Tutor, Tutee, Tutorial.

\footnotetext{
1 Postgraduate student at the Department of Preschool Education and Social Work at Bogdan Khmelnitsky Melitopol State Pedagogical University, Melitopol, Ukraine. https://orcid.org/00000002-5184-9907 E-mail: spodpleta@gmail.com
} 


\section{Introduction}

The modern system of education in Ukraine is in an active search for new forms and methods for improving the efficiency of mastering the knowledge at different levels and in various educational systems. There is a very fast accumulation of information in modern society. Contemporary psychological and pedagogical science is constantly faced with the need to reorganize the methods and forms of teaching and learning. There is a conflict between the requirements for the education of modern times and the predominance of lectures in education. Students study less, use the knowledge gained in practice worse, and are at a loss what to do in unusual problem situations.

Educational theorists and experts are engaged in an active search for new educational strategies and project development. The conditions for improving the effectiveness of education, based on the implementation of cooperation pedagogy and the principles of equal interaction of participants in the educational process, are actively studied. Such pedagogical phenomena as students' self-actualization and self-determination, independent thinking and self-confidence are presented in numerous works such as Dawson and Venville (2010) and Bërveniku (2017). After all, reasonable argumentation is an indicator of students' mental and cultural maturity (Driver, Newton \& Osborne, 2000; Öztürk, 2017; Lin \& Mintzes, 2010). Modern schoolchildren often have a low motivation for cognitive activity. As a result, students have difficulty with evaluating arguments (Kristianti, Ramli, \& Ariyanto, 2018).

Cognitive preconditions and age peculiarities for the argumentative skills improving are determined in modern studies (Andrews, 2010; Golder, 1996; Kuhn, 2001; Lupton, 2008; Simon, 2008; Okada \& Shum, 2008; Çetinkaya \& Tasar, 2017). The decisive role of social interactions in brainbuilding is theoretically and experimentally substantiated, and the specifics of argumentation in the situations of collective problem solving are investigated (Inglis \& Mejia-Ramos, 2009; Ravenscroft \& McAlister, 2008; Rapanta, 2018). The argument is considered as a social and cultural resource (Rigotti \& Morasso, 2010; Erduran \& Jimenez-Aleixandre, 2008; Karaslaan, Hohenberger, Demir, Hall \& Oaksford, 2018; Hornikx \& Hoeken, 2007; Hornikx \& ter Haar, 2013), as a means of activating the educational process in the system of secondary and higher education (Albano \& Dello, 2019; Ragonis \& Shilo, 2018; Schwarz \& Baker, 2016; Albe 2008; Simon, Erduran \& Osborne, 2006).

Although the literature review reveals numerous publications, the possibilities of argumentation aren't sufficiently introduced in the educational process. Meanwhile, there are grounds to speak not only about the methods of argumentation but about the argumentative technologies in education. The reference should be made to a reinterpretation of pedagogical argumentation. The argumentative discourse, implemented in pedagogical communication, is a fertile ground for research and development of teaching technologies. The argumentative discourse provides students' self-actualization. Students also reveal the meanings of their own activities and behaviors through the argumentative discourse, entering into dialogue with each other. These dialogues introduce the problem of consciousness and behavior, attitudes and actions of the individual.

Kuhn (1991) describes an argument as "an assertion with accompanying justification". Means and Voss (1996) define it as "a conclusion supported by at least one reason". According to Berland \& Reiser (2009), argumentation is a social activity that helps an individual to interpret the knowledge. Toulmin (1958) defines it as a process that produces theories or assertions and provides support and justification by way of evidence. Hyland (2004) describes argumentation as the act of forming reasons, making inductions, drawing conclusions and applying them to the case in discussion. Despite the many interpretations of the argumentation, the general for them is the rendering of the latter as a verbal and cogitative activity associated with the ways to give one's point of view and the notion of 
conviction. Argumentation is an important practice in science. Scientists are developing knowledge by testing scientific claims, considering pieces of evidence, and assessing alternative explanations (Berland \& Mcneill, 2010). Traditionally, argumentation is regarded as an integral part of logic, which is a way of rational persuasion of people in a discussion, polemic, or dispute. In a communicative way, argumentation is the process of information transferring and interpreting to the recipient. The purpose of argumentative discourse teaching is the formation of certain monologue skills for correct, logical, consistent, and creative use of learned language material for thought expressing. Noticeably, several disciplines - psychology, logic, rhetoric, linguistics - are immediately involved in the process of studying the argumentation.

These characteristics of the argument determine its widespread use in the development of social relations and models. Means and methods of argumentation as a technology of persuasion are used in such social spheres as marketing, advertising management, copywriting, journalism, where there is a need to influence the views and beliefs of the audience through language. The theoretical questions concerning the role of argumentation in these areas are covered in a number of papers; practical methods of argumentation as a technology of influence are used in seminars and trainings.

It is usually difficult for students to formulate arguments because of the limited time for learning, personal characteristics, poor linguistic experience, or lack of interest. These reasons can be corrected by using new innovations in the learning process. A person-centered approach, which provides the most favorable conditions for the development and self-realization of the individual, becomes a priority in education. It intends to create a partnership, subject-subject relations, and dialogic communication. The role of teacher and student is equalized in partnership relationships. The idea of cooperation and partnership is one of the main in the pedagogy of recent years. The tutorial system of education attracts particular attention in Ukraine as an innovative element. It is practiced in most of the developed countries.

The tutoring system is a complex of forms, means, methods, and principles that stimulate the student's intellectual and moral development. Tutor actively promotes self-development and selfeducation of the tutee, the ability and readiness for the development of the system of social roles. Tutor teaches students to think not only independently but also self-consciously through a variety of activities, mass reading and writing, active participation in critical discussions that include selfimmersion, self-analysis, self-correction, and mental flexibility. Through reading and researching, writing and presenting, discussing and correcting, reformulating arguments, cautiously and gradually, week by week, semester by semester, year after year, students learn to think independently and refine their argumentation skills. The function of the tutorial is to educate people who are able to survive and adapt to rapid changes and to adjust their mental abilities to the new world (MayrHarting, 2006).

Thus, tutors improve students' argumentation skills in a certain area of knowledge, train thinking and improve learning. For forming the experience of argumentation they also use a number of techniques to provide a motivated student initiative to solve a certain verbal and cogitative problem. Essay writing and discussion are the most commonly used among them. D. Sabri (2007) proved the importance of essays for improving the ability of students to argue. She defines a good essay as "incisive, precise, concise, critically evaluating arguments, containing personal interpretation and demonstrating independence of mind". The main purpose of the tutor's activities is to train the ability to make good arguments.

\section{Methodology}

The article is devoted to peculiarities of applying the tutor's questioning techniques and writing essays in teaching argumentation to secondary school students. The research is aimed at 
identifying the most effective ways and means of applying the given methods. According to the hypothesis, regular tutorials in secondary schools should promote the improving argumentative skills of students.

The research was conducted in three schools within the framework of the scientific and pedagogical project "School of Excellent Tutoring" on the basis of the Ministry of Education and Science of Ukraine order № 730 (June 30, 2016) "About Conducting an All-Ukrainian Experiment on the Implementation of the Scientific and Pedagogical Project "School of Excellent Tutoring"'". The experimental sample comprised three groups of pupils at the age of 16-17 of schools in Melitopol and Vasylivka town. The total number of students is 36 (19 girls and 17 boys). The students with mixed academic achievement and abilities attended tutorials. Tutorials in groups were conducted using an experimental method. Tutors met with tutees once a week, from September to May 20182019 (32 weeks, 64 hours).

Tutorials were devoted to moral and ethical problems or dilemmas, which provided for the ambiguity of judgments and conclusions. Tutors announced topics of the meetings a week before tutorial, so that the students had the opportunity to prepare and find the necessary information. Each student had to bring an essay that had been written at home. Students presented their essays during tutorials. After that tutors put questions to students forcing them to think in potentially useful directions. The questions at tutorials were used for motivating students to search for causes and to demonstrate their understanding and awareness. According to the research hypothesis, an experimental training course should improve the argument skills of students.

The complex of modern general scientific methods has been used for task realization: theoretical methods - analysis and synthesis; empirical methods - observational (direct and indirect observation); diagnostic (expert interviews, conversations); methods of experimental-theoretical level; methods of mathematical statistics.

Reliability of the research results is ensured by methodological substantiation and consistency of the initial theoretical positions, the development of an experimental teaching methodology, adequate to the goal and objectives of the study, the correct organization of experimental work, which includes the training experiment and the analysis of students' dialogues, the practical confirmation of the main provisions of the study and the careful processing of the results obtained in during an empirical study of data.

\section{Results}

At the beginning of the experiment, the students of the upper classes of the three secondary schools were asked to write down essays and present them. The results of the students' work were evaluated according to two criteria: logical skills, language skills.

As a result, there weren't any skills of analysis in the vast majority of students. They could not highlight the essential features of a phenomenon and also generalize them. Accordingly, only $59 \%$ of students were able to identify and formulate the thesis of texts. More than $39 \%$ of the students had significant difficulties with selecting arguments. The vast majority (56\%) confined to one argument or judgment, the truth of which was questionable, or used examples instead of arguments. There were two or more arguments in a small number of works, but they were constructed chaotically. Accordingly, $44 \%$ of students disrupted the demonstration process. They made shortcomings in the process of linking arguments with the justification of the thesis. The loss or substitution of the thesis was the most common logical mistake. The students didn't try to prove the initial position, but the other that appeared in the process of reasoning. Thus, the purpose was not achieved, and there were problems with the formulation of the conclusion, which, of course, was far from the thesis or was absent. 
Only a third of the essays had a tripartite composition. There wasn't paragraph division in such works. The composition skills were not developed in a proper way. One way or another, $64 \%$ of students showed the ability to plan and make a statement correctly. The survey also showed a fairly low level of contact with the audience: $42 \%$ of the students used introductory constructions, complex sentences, and means of verbal expression in the process of argumentation.

Thus, the analysis of written essays and speeches of the students made it possible to conclude that students had poor reasoning skills. Knowledge of students was not systematic and was isolated from the practice of everyday communication. There weren't elementary logical skills in the vast majority of students.

Subsequently, students attended tutorials during the school year, which were based on principles such as functional-semantic, which involves the conscious use of speech units in conversation; the principle of developmental teaching, based on the activation of mental activity of students and independent search for the right solutions; the principle of the connection between theory and practice, the obligatory condition of which is the application of the acquired knowledge in practical training and professional activity; the principle of consciousness and activity, according to which students must become not only the object but also the subject of activity for educational attainment; the principle of upbringing, which requires the formation of ideology, a proactive approach to life and civic stand; a communicative principle that provides the active involvement of students in linguistic activities.

At the tutorials, the tutors worked with the students from the experimental group on the primary logic of analysis and synthesis, developed the ability to formulate concepts and developed the language skills of constructing sentences and essays using expressive means of speech: rhetorical figures, tropes, phraseological units, artistic images, quotations. The aim of the tutors was to organize the process of mastering the oral reasoning in order to maximally motivate the linguistic activity of the students.

At first, the tutors in every way encouraged verbal statements of students. Oral reasoning was an obligatory practice of each tutorial. Tutees knew the theme of the tutorial in advance and prepared an essay at home. Essays were presented at the tutorial. A heuristic discussion was the compulsory component of any tutorial, which facilitated gaining knowledge. At the same time, students had to use the methods of analysis of the phenomenon under study, observing it from different perspectives.

The final stage of training the argument was also based on an essay, which served only for the production of own statement, created motivation and provided material for mental operations. At this stage, the tutors were very demanding regarding the linguistic and intonational presentation of the statement. The method of collective analysis of the performance was used, in which students were asked to evaluate the performance of a friend in terms of logic, expressiveness, and contact with the audience. In addition, an audio recording of students' performances was used, followed by listening so that they could independently assess the advantages and disadvantages of their monologues.

After the experimental training course with tutors, a re-examination was conducted on the level of formation of argumentative skills. As a result, students improved their analysis skills. $89 \%$ of tutees were able to formulate correctly the thesis, which suggested an improvement in the skills of inductive thinking. $81 \%$ of students coped with the selection of arguments and facts. Only $14 \%$ of tutees used one argument or judgment, the truth of which was questionable, or used examples instead of arguments. The arguments were interrelated in $94 \%$ of the works. $92 \%$ of students made a statement correctly. More than $83 \%$ of tutees kept the attention of the audience alive, using the 
means of verbal expression in the process of argumentation. The results of the level of formation of the argument skills before and after the end of the experiment are presented in the table.

Table 1. Development of argumentative skills

\begin{tabular}{|l|c|c|}
\hline \multicolumn{1}{|c|}{ Argumentative Skills } & \multicolumn{2}{c|}{ Percentage of students completed the assignment } \\
\cline { 2 - 3 } & Initial & 89 \\
\hline Creating a thesis statement & 59 & 81 \\
\hline $\begin{array}{l}\text { Selection of arguments and } \\
\text { facts }\end{array}$ & 61 & 86 \\
\hline Sufficiency of argumentation & 44 & 94 \\
\hline $\begin{array}{l}\text { Establishing a cause-effect } \\
\text { relationship }\end{array}$ & 56 & 92 \\
\hline Clear-cut statement & 64 & 83 \\
\hline $\begin{array}{l}\text { Keeping the attention of the } \\
\text { audience alive }\end{array}$ & 42 & \\
\hline
\end{tabular}

\section{Discussion}

As the results indicate, forming argumentative skills at secondary school is possible in tutorials. Tutorials facilitate a significant speech improvement and development argument skills of tutees. This allows us to conclude that it is necessary to include tutorials in the active practice of educational institutions of Ukraine. Tutors are the bearers of spiritual, moral and cultural values. They realize values in professional activities. They try to understand every student, choose an individual trajectory of motion with the tutee. The position of the tutor plays an important role in the formation of a new educational space, which determines a steady positive motivation to students' self-education.

This study presents evidence about the necessity to increase the number of tutorials for students of secondary school where they can improve argumentative skills. At the same time, they should have not only profound theoretical knowledge but also have practical experience. Tutors teach tutees to be self-reliant in learning and decision-making to cope with constant change and diversity. Essay writing and discussions in a group are designed to develop students' abilities to argue their own position, encourage reflection, promote the acquisition of critical thinking skills, reveal metacognitive perspectives and achieve the ability to think independently (Beck, 2008).

Meeting with a tutor is fruitless without writing an essay. As Mayr-Harting (2006) states "no essay, no tutorial". Students express their own thoughts on different topics: the meaning of life, moral values, their purpose, attitude to others, etc. While presenting their essays, students act like teachers. Realizing that an experienced person will be listening to them, tutees must be ready to defend their proposed assumptions and evidence. Acting like a teacher, students learn to think for themselves. So students agree that it is useful for them to teach each other.

Discussion, as one of the main methods of tutorials, should take place on the basis of coaching principles. Tutors mostly use open questions. Such a discussion facilitates the development of the thinking ability, imaginative capability, inquisitiveness and creativity of the students. A tutor must be able to listen carefully and create trusting relationships, avoiding the directivity. The basis of the dialogue is a common search for problem-solving in which the participants of the dialogue can express their assumptions and defend their own point of view on an equal footing. Communication 
conditions should be well-organized in order that participants feel their success and intellectual autonomy. In general, discussions on tutorials should have not only educational but also emotional effects in order to further make it possible to conduct an in-depth analysis of the educational situation of each student. As soon as a student expresses his or her views, a tutor put questions. In this way, there is an exchange of information and thoughts. Students must be able to defend their beliefs. At this time, their mental abilities are adjusted to comprehend the information that underlies their conversation with the tutor. Students are undergone through the ritual of self-criticism, which destroys his or her arguments, and at this moment he or she realizes the mistake, feels it emotionally, as if it is transformed mentally.

Many scientists believe that student's arguments can be trained through teachers' questions in learning progress (Erdogan, Ciftci \& Topcu, 2017; Ragawanti, 2009; Chin, 2004; Beatty, Gerace, Leonard \& Dufresne, 2008; Eemeren \& Houtlosser, 2007). With the help of questions, one can bring the student to certain conclusions. The collision of opposite points of view contributes to the development of the ability to organize a mental activity, basic language skills, empathy and tolerance to different perspectives, ability to work in a team, logical and critical thinking, self-confidence and development of arguments in students. Through the tutorials, students formed the ability to conduct debates without trying to overthrow the opponents' arguments to prove their failure, but in order to work on their own system of evidence, and through the exchange of arguments, to solve particular problems. The practice of conducting tutorials showed that students are actively involved in the process; follow the rules of debates, which allowed arranging students' arguments and getting great experimental material.

A contemporary student, unsystematically and discretely informed on a variety of issues, is not capable of consciously forming his or her personality and often experiences some difficulties in understanding the world. There is the presentation of individual positions in students' questions to each other and to the tutor. Students usually ask what makes sense to them. It should be emphasized that the tutor's activities in this situation should be distinguished by increased tact for the students and attention to their questions since the students are psychologically easily vulnerable. The mutual respect to the thought of each other is very important. Tutor accepts the student just the way he or she is since the correction of individual qualities is possible only on the basis of a general positive attitude towards the student's integral personality. Due to the subject-subject model of the educational process at the tutorials, the tutor is able to accept the student with his or her pluses and minuses, with possibly ambiguous world-view orientation. Tutor hesitates to tell truth, giving the opportunity to express and develop in dialogue student's personality, to form his or her position and find answers to questions. The interest in student's success and the favorable environment of argumentative discourse, contributes to self-actualization and development of the student. This kind of relationship between the subjects of the educational process is an important condition for the individualization of education.

The following recommendations are intended for cognitive-stylistic peculiarities of students' argumentation in tutor's activity and are oriented on the content and individualization of the educational process:

1. It is important for the tutor to pay special attention to the individual cognitive-style features of students' arguments and widely used argumentative discourse in the practice of teaching. Such a discourse can be conducted both in oral and writing forms of tasks for improving argumentative skills.

2. The tutor should analyze the language occurrences of arguments and the semantic level of student speech organization in the verbal and cogitative aspects of teaching. 
3. In order to improve the efficiency of learning, the tutor can identify the cognitive-style features of students by setting a number of questions that require an argumentative response.

4. In practice, during the explanation of the educational material, the tutor is recommended to use different methods of argumentation since the training groups are heterogeneous.

5. It is important to encourage students to demonstrate communicative and linguistic competence, to argument their answers, as well as to draw attention to the fact that the student's personality can be considered directly in the acts of speech interaction, in the practice of argumentative discourse.

6. The tutor must remember that argumentation, as a way of student's self-realization, takes place in a huge stream of language. There are a lot of argumentative meanings in each student's phrase. One of the most important tasks of differentiated person-oriented teaching is the ability of the tutor to use knowledge of the cognitive-style typology and specifics of the argumentation.

\section{Conclusion}

Mastering the practical skills of argumentation is an essential prerequisite for the formation of a modern personality. As part of the educational process, argumentative skills that shape not only the culture of language but also the culture of thinking contribute to the successful mastering of learning material. In the future professional activity, the argumentative skills are necessary for career development, as they allow defending own position, influencing the behavior of colleagues and subordinates, promoting authority. In addition, they promote the development of certain social guidelines and open prospects of self-realization.

The results of the experimental work suggest a framework for confirming the advisability of the use of the proposed methodology, which contributes to the development of a coherent monologue speech of students and gave an impetus to further improvement of their linguistic, argumentative and intellectual skills that can be applied in all areas of professional and public activity. Students, taking an active part in tutorials, develop the ability to structure arguments, listen to each other, formulate counterarguments, and seek information. The opponents' questions and counterarguments start the process of shifting the position in students' arguments and socialize their thinking. The rules of conducting debates allow reconsidering students' position and looking for the grounds for the proof of this or that statement.

Thus, the tutorial is an effective opportunity to work out the theoretical foundations of argumentation, form a research interest and develop the skills of ethical expression of one's own position.

\section{References}

Albano, G., \& Dello lacono, U. (2019). A scaffolding toolkit to foster argumentation and proofs in mathematics: some case studies. International Journal of Educational Technology in Higher Education, 16, 4. DOI: 10.1186/s41239-019-0134-5.

Albe, V. (2008). When scientific knowledge, daily life experience, epistemological and social considerations intersect: students' argumentation in group discussion on a socioscientific issue. Research in Science Education, 38(1), 67-90. DOI: 10.1007/s11165-007-9040-2.

Andrews, R. (2010). Argumentation in higher education: Improving practice through theory and research. London: Routledge.

Beatty, I. D., Gerace, W. J., Leonard, W. J., \& Dufresne, R. J. (2008). Designing effective questions for classroom response system teaching. American Journal of Physics, 74(1), 31-39. DOI: $10.1119 / 1.2121753$ 
Beck, R. J. (2008). The pedagogy of the Oxford tutorial. Retrieved from http://www2.lawrence.edu/fast/beckr/pdfs/OxfordTutorial_7_05_06.pdf.

Berland, L. K., \& Reisier, B. J. (2009). Making sense of argumentation and explanation. Science Education, 93 (1), 26-55. DOI: 10.1002/sce.20286.

Berland, Leema \& Mcneill, Katherine. (2010). A Learning Progression for Scientific Argumentation: Understanding Student Work and Designing Supportive Instructional Contexts. Science Education, 94, 765 - 793. DOI: 10.1002/sce.20402.

Bërveniku, E. D. (2017). The Art of Argumentation: A Sociolinguistic Approach to Developing Thesis Statements (The Case of Kosova High School Students). Eurasian Journal of Applied Linguistics, 3, 271-286. DOI: 10.32601/ejal.461018.

Çetinkaya, E., \& Tasar, F. (2017). Fen Bilimleri Eğitimi Alanında Türkiye Merkezli Argümantasyon Araştırmalarının Çeşitli Değişkenler Açısından İncelenmesi. Hacettepe University Journal of Education, 1-29. DOI: 10.16986/HUJE.2017030625.

Chin, C. (2004). Student's questions: fostering a culture of inquisitiveness in science classrooms. School Science Review, 86(314), 107-112.

Dawson, V.M. \& Venville, G. (2010). Teaching Strategies for Developing Students' Argumentation Skills About Socioscientific Issues in High School Genetics. Research in Science Education, 40, 133144. DOI: 10.1007/s11165-008-9104-y.

Driver, R., Newton, P., \& Osborne, J. (2000). Establishing the norms of scientific argumentation in classrooms. Science Education, 84(3), 287-312. DOI: 10.1002/(SICI)1098237X(200005)84:3<287::AIDSCE1> 3.0.CO;2-A.

Eemeren, F. H. Van, \& Houtlosser, P. (2007). Dialectical profiles and indicators of argumentative moves. OSSA Conference Archive, 37.

Erdogan, I., Ciftci, A., \& Topcu, M. (2017). Examination of the questions used in science lessons and argumentation levels of students. Journal of Baltic Science Education, 16, 980-993.

Erduran, S., \& Jimenez-Aleixandre M. P. (2008). Argumentation in Science Education: Perspective from Classroom-based Research. Dordrect, Netherlands: Springer.

Golder, C. (1996). The development of argumentative discourse. Neuchatel: Delachaux et Niestle.

Hornikx, J., \& Hoeken, H. (2007). Cultural differences in the persuasiveness of evidence types and evidence quality. Communication Monographs, 74, 443-463. DOI: 10.1080/03637750701716578.

Hornikx, J., \& ter Haar, M. (2013). Evidence quality and persuasiveness: Germans are not sensitive to the quality of statistical evidence. Journal of Cognition and Culture, 13, 483-501. DOI: 10.1163/15685373-12342105.

Hyland, K. (2009). Writing in the disciplines: Research evidence for specificity. Taiwan International ESP Journal, 1(1), 5-22.

Inglis, M., \& Mejia-Ramos, J. P. (2009). The effect of authority on the persuasiveness of mathematical arguments. Cognition and Instruction, 27(1), 25-50.

Karaslaan, H., Hohenberger, A., Demir, H., Hall, S., \& Oaksford, M. (2018). Cross-cultural differences in informal argumentation: Norms, inductive biases and evidentiality. Journal of Cognition and Culture, 18(3-4), 358-389. DOI: 10.1163/15685373-12340035

Kristianti, T., Ramli, M., \& Ariyanto, J. (2018). Improving the argumentative skills of high school students through teacher's questioning techniques and argumentative assessment. Journal of Physics: Conference Series. DOI: 10.1088/1742-6596/1013/1/012012

Kuhn, D. (1991). The skills of argument. Cambridge: Cambridge University Press. 
Lin, S. S., \& Mintzes, J. J. (2010). Learning argumentation skills through instruction in SSI: The effect of ability level. International Journal of Science and Mathematics Education, 8, 993-1017.

Lupton, M. (2008). Evidence, argument and social responsibility. Higher Education Research \& Development, 27(4), 399-414.

Mayr-Harting, H. (2006). The Oxford Tutorial. Convocation Curriculum delivered at Lawrence University, Wisconsin. November.

Means, M., \& Voss, J. (1996). Who reasons well? Two studies of informed reasoning among children of different grade, ability, and knowledge levels. Cognition and Instruction, 14(2), 139-178. DOI: 10.1207/s1532690xci1402_1.

Okada, A., \& Shum, S. B. (2008). Evidence-based dialogue maps as a research tool to investigate the quality of school pupils' scientific argumentation. International Journal of Research \& Method in Education, 31(3), 291-315.

Öztürk, A. (2017). An investigation of prospective science teachers' socio-scientific argumentation processes in terms of metacognition: A causal-comparative study. Pegem Eğitim ve Öğretim Dergisi, 7(4), 547-582, DOI: 10.14527/pegegog.2017.020.

Ragawanti, D. T. (2009). Questions and questioning techniques: A view of Indonesian students' preferences. K@ta, 11,155-170. DOI: 10.9744/kata.11.2.155-170.

Ragonis, N., \& Shilo, G. (2018). Analogies between Logic Programming and linguistics for developing students' understanding of argumentation texts. Journal of Information Technology Education: Research, 17, 549-575. DOI: 10.28945/4163.

Rapanta, C. (2018). Teaching as Abductive Reasoning: The Role of Argumentation. Informal Logic, 38(2), 184-311. DOI: 10.22329/il.v38i2.4849.

Rapanta, C. (2019). Argumentation as Critically Oriented Pedagogical Dialogue. Informal Logic, 39(1), 1-31. DOI: 10.22329/il.v39i1.5116

Ravenscroft, A., \& McAlister, S. (2008). Investigating and promoting educational argumentation. International Journal of Research \& Method in Education, 31(3), 317-335.

Rigotti E., Greco Morasso S. (2009) Argumentation as an Object of Interest and as a Social and Cultural Resource. In: Muller Mirza N., Perret-Clermont AN. (eds.) Argumentation and Education. Boston: Springer.

Sabri, D. (2007). Students' experiences of the formative assessment of essays in history and archaeology at Oxford. Oxford Learning Institute.

Schwarz, B. \& Baker J. M. (2016). Dialogue, Argumentation and Education: History, Theory and Practice. New York: Cambridge University Press.

Simon, S. (2008). Using Toulmin's Argument Pattern in the evaluation of argumentation in school science. International Journal of Research \& Method in Education, 31(3), 277-289.

Simon, S., Erduran, S., \& Osborne, J. (2006). Learning to teach argumentation: research and development in the science classroom. International Journal of Science Education, 28(2-3), 235-260. DOI: 10.1080/09500690500336957.

Tellis, G. J. (2004). Effective Advertising: Understanding when, how, and why Advertising Works. Thousand Oaks, CA: Sage Publications.

Toulmin, S. (1958). The uses of argument. Cambridge: Cambridge University Press. 